\title{
ePAL Roadmap for Active Ageing
}

\section{A Collaborative Networks Approach to Extending Professional Life}

\author{
Luis M. Camarinha-Matos \\ Faculty of Sciences and Technology \& UNINOVA \\ Universidade Nova de Lisboa \\ 2829-516 Monte Caparica, Portugal \\ cam@uninova.pt
}

\author{
Antonio del Cura \\ SKILL Estrategia SA \\ Seville, Spain \\ adelcura@skill.es
}

\author{
Hamideh Afsarmanesh \\ Computer Science Department \\ University of Amsterdam \\ Amsterdam, The Netherlands \\ h.Afsarmanesh@uva.nl
}

\author{
Jim Playfoot \\ White Loop Limited \\ London, UK \\ jim@whiteloop.com
}

\begin{abstract}
Active ageing, through a balanced combination of leisure and social interaction with continued work involvement, is central to meeting older citizens expectations, and maintaining their mental and physical health. Application of the collaborative networks paradigm, and the new generation of collaborationsupport platforms and tools, can offer a promising approach to supporting active ageing, and can facilitate better use of the talents and potential of retired or retiring senior professionals. This paper introduces the results of a roadmapping initiative addressing the implementation of a new vision for extending professional active life. To support this vision, a strategic research plan for the development of a new digital ecosystem, covering the social, organizational, and technological perspectives, is proposed. A large number of stakeholders coming from different backgrounds have contributed to the design and validation of this roadmap.
\end{abstract}

Keywords - collaborative networks, active ageing, roadmap.

\section{INTRODUCTION}

Many recent studies have highlighted the prevailing demographic shift towards an older and healthier population [1]. The challenges posed by an ageing society have been thoroughly discussed, particularly in terms of care needs and social costs [2]. It is also a reality that many elderly citizens, following retirement, quickly become marginalized, losing most of their social links which leads to loneliness, and to them being considered as a cost burden rather than a resource that is capable of "value creation" in the society. And yet retired senior professionals represent an important source of experience, wisdom, and talent and many of these seniors would be willing and enthusiastic about to continuing to contribute to society and the economy.

Furthermore, active ageing, through a balanced combination of leisure, social interaction, and continued work involvement, is central to meeting citizen expectations and maintaining mental and physical health [3].

Permission to make digital or hard copies of all or part of this work for personal or classroom use is granted without fee provided that copies are not made or distributed for profit or commercial

advantage and that copies bear this notice and the full citation on the first page. To copy otherwise, to republish, to post on servers or to redistribute to lists, requires prior specific permission and/or a fee. PERVASIVEHEALTH 2010, March 22-25, Munchen, Germany

Copyright $(\odot)$ 2010 ICST 978-963-9799-89-9

DOI 10.4108/ICST.PERVASIVEHEALTH2010.8863
The critical challenge for society in respect of the "active ageing / ageing well" process is to identify new organizational structures, approaches, and mechanisms - and to support these with relevant technologies - to avoid the exclusion of senior citizens from the market/society, and to promote the use of their knowledge and expertise in making valued contributions. In addition to the traditional initiatives focused mostly on socialization and entertainment activities for elderly, a number of other organizational forms and mechanisms are emerging, focused on helping seniors remain professionally active, after their retirement.

In recent years the term silver economy has gained some notoriety although it has been used in a very restricted perspective, mainly referring to the business of providing services to the elderly. However, this view of seniors as just "consumers" with some financial capacity is quite limited and a more comprehensive perspective of the term should encompass the direct contribution seniors can make to value creation in society.

ICT, and particularly high-speed pervasive broadband connectivity and web-based technologies, offer new opportunities to create new ways of working, facilitate social interaction, and reduce limitations imposed by location and time, thus increasing personal control. Certainly a good number of ideas have been tried out in many research projects and pilot experiments on ICT and ageing. A good portfolio of results and lessons learned are already available. But many good ideas and promising pilot cases also fail to scale because the wrong priorities were chosen at the wrong time or a more holistic framework was missing. The sensitivity of the area, the dependency on the "parallel" introduction of new organizational models and creation of a new culture in society, the lessons learned with the limited success of existing associations of senior professionals, the risk of continuously developing technology that is not taken-up by target users, among others suggest the need for a careful analysis and a better planned approach towards what concerns new developments. In this context, roadmapping plays a 
fundamental role in the identification of a strategic research agenda and prioritization of needed actions.

In order to elaborate a strategic RTD plan in this direction a 27month European initiative - ePAL (extending Professional Active Life) project - was launched in 2008 [4]. ePAL aims to explore innovative ways to best facilitate and support active ageing and ensure a balanced and inclusive post-retirement lifestyle (Fig. 1). A major hypothesis followed in ePAL is that ICT and particularly collaborative networks can provide an adequate framework for the implementation of effective support to active ageing [5].

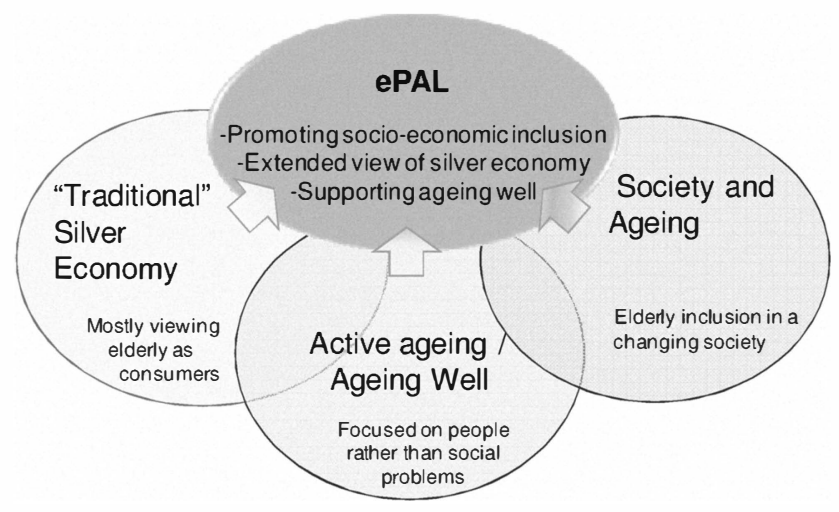

Figure 1. ePAL's approach to active ageing

A technology-only centred approach, without a comprehensive vision and consideration of the socioorganizational aspects is likely to, at best, add only marginal value. Addressing the need for organizational and cultural change is fundamental to ensuring that stakeholders are ready to face the challenges and embrace the new opportunities offered by technology. Without proper attention to organizational readiness we cannot realize the full benefit of the technology potential [6]. Therefore, the plan of R\&D actions proposed by ePAL is based on an ambitious vision for extending active professional life and addresses not only the technological developments but also the social and organizational aspects.

\section{ROADMAPPING METHOD}

A meaningful roadmap needs to be the result of contributions from relevant visionaries and stakeholders in the field. In order to properly integrate and put in the right context the various contributions, it is important to follow a set of systematic steps.

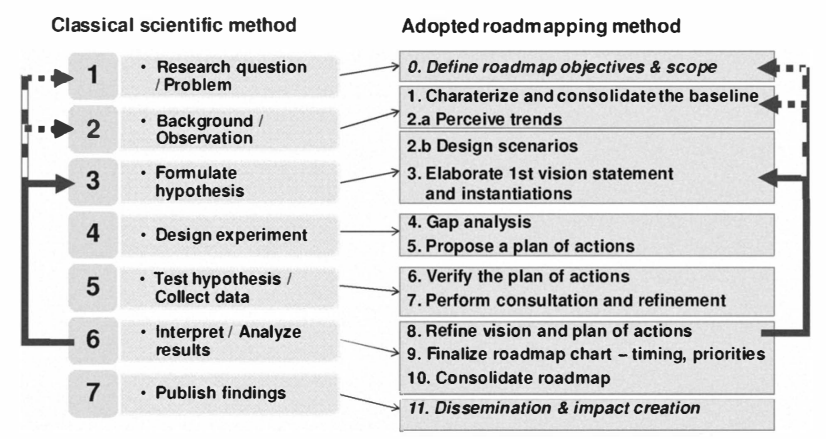

Figure 2. A systematic roadmapping method
Our roadmapping method is adapted from the "standard" scientific method (Fig. 2) and has proven to be effective in various projects [7].

Three main elements need to be defined in a research roadmap: current situation and trends (baseline), desired vision, and plan of (research) actions (Fig. 3).

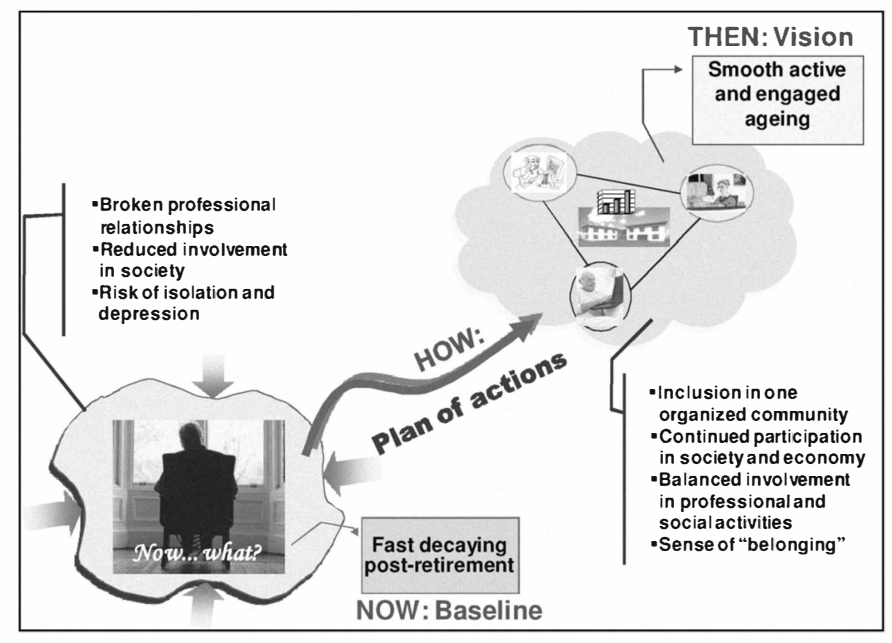

Figure 3. Main elements for the ePAL roadmap

\section{BASELINE}

As part of the baseline characterization phase of the roadmapping process, an extensive analysis of the existing associations of senior professionals was conducted. Table 1 shows the list of those that either took part in the survey or actively contributed to the ePAL workshops.

These associations are mostly composed of the "professional elite" (people with a high level education background and that held senior management positions before retirement). In most cases, these people have reasonable pensions (although varying from region to region) and therefore can afford to do voluntary (unpaid) activities. However, the number of people involved is not very high. On the other hand, considering the current difficulties of the social security systems all over Europe, most governments are trying to implement new formulae for pension calculation which in practice
TABLE 1. Studied associations of senior professions

\begin{tabular}{|c|c|}
\hline Organization & Country \\
\hline AGIRabcd & France \\
\hline APCS & Portugal \\
\hline ASECAT & Colombia \\
\hline ASEP & Austria \\
\hline BSC-I & Belgium \\
\hline COGAMA & Spain \\
\hline CONFEMAC & Spain \\
\hline CONJUPES & Spain \\
\hline ECTI & France \\
\hline EGEE & France \\
\hline FRAE & Spain \\
\hline ISES & Italy \\
\hline JUBIQUÉ & Spain \\
\hline KOS & Poland \\
\hline NESTOR & Finland \\
\hline OTECI & France \\
\hline PUM & Netherlands \\
\hline REACH & UK \\
\hline RSVP & UK \\
\hline SECOT & Spain \\
\hline SEN@ER & Spain \\
\hline SENA & Belgium \\
\hline SENIORES & Italy \\
\hline SES & Germany \\
\hline SFPA & Slovenia \\
\hline SHARE & Portugal \\
\hline SWB & Denmark \\
\hline UDP & Spain \\
\hline Vis VITALIS & Poland \\
\hline & \\
\hline
\end{tabular}


means a reduction of the pension. In such a context, it is foreseeable that more retirees will have fewer resources than needed to satisfy their standard of life and thus will need to continue involvement in value creation activities.

Most of the studied organizations, in spite of their ambitious mission statements, operate on a relatively passive basis, basically "expecting the client or the business opportunity to show up". As a consequence, they do not have many projects. A frequent complaint we encountered is that they do not have enough work for all their members. And yet, many SMEs and start-ups world-wide that cannot afford to pay market prices for consultancy and coaching, could greatly benefit from the accumulated knowledge and experience of senior professionals. But there are clearly challenges in reaching potential clients due to the lack of appropriate brokerage mechanisms or the requisite support of intermediary entities.

In addition to these associations, various other mechanisms and practices to support active ageing can be found. Examples include the maintenance of some links to the former employer (as in the case of jubilee professors), free-lancing, time bank, etc. Free-lancing is a typical option for those who wish to continue involvement in some form of remunerated activity. Nevertheless it represents an individual initiative, requiring some degree of entrepreneurial spirit that not all retirees are able to exercise. It also requires some preparation for which training is not easily available. Most of these professionals have developed their careers in the context of an organization and are not prepared to undertake consultancy work.

Further to the need to move from voluntary (only) activities to (some options of) paid work, it is also important to find new forms of "socialization", a critical issue after retirement for which collaborative networks can be an answer. Fig. 4 illustrates this situation and foreseeable trends [5].

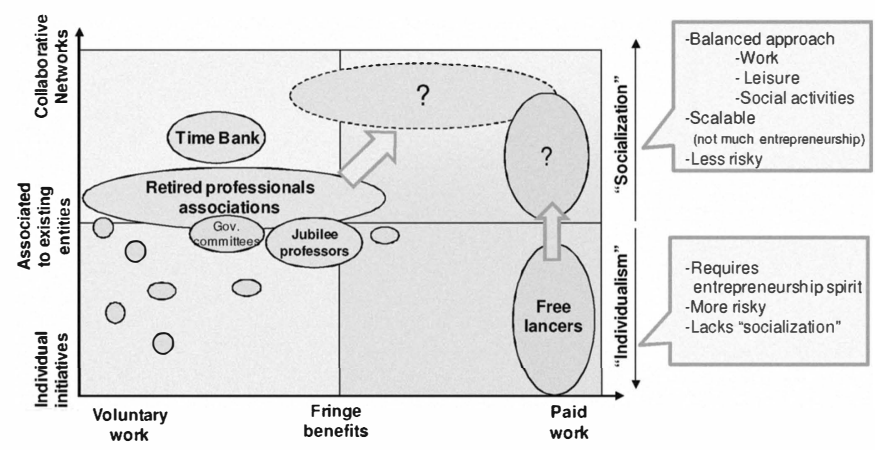

Figure 4. Panorama of approaches in active ageing

\section{VISION AND ITS INSTANTIATIONS}

The application of vision in defining and shaping the future direction of an organization or a society is increasingly becoming popular in today's world. A vision defines a desired future, while strongly interconnected with the framework that underlies the organizations or societies [8]. It is a deeply held picture of where a person, a group of people, an organization, or a society, wants to reach in the future. We create meaning in our lives by pursuing our future visions, and we refine our visions based on the meaning we are discovering through our experience. A vision is the most inspiring future the society can imagine. Because of this ambitious prospect, the society can never truly achieve its vision. It works toward that vision.

A fundamental prerequisite for developing a vision for the desired future of this area is to identify both: the key drivers (i.e. the main driving forces in the market and society) and their related trends regarding the ePAL environment. A wellconceived vision consists of two major components, namely, the core ideology and the envisioned future [9]. Core ideology is the first primary component of the vision framework which consists of two parts: core values and core purpose. Core values are the essential and enduring tenets of an organization or a society. Core values have intrinsic value and importance to those inside the organization or society. Core purpose however points to certain fundamental reason for society to exist. An effective purpose reflects the importance that people attach to daily activities of the organization or society. Envisioned future is the $2^{\text {nd }}$ primary component of the vision framework which consists of 2 parts: a long-term audacious goal and a vivid description or desired facets of what it will be like when goals are achieved.

\section{TABLE 1. General vision statement}

\section{Core ideology:}

Building strong and cohesive societies across Europe that embrace active senior professionals to create value for individuals, communities and the economy

\section{Envisioned future:}

In the coming decade, a comprehensive paradigm will emerge in response to the challenges of demographic shift in Europe that enables a balanced active life for senior professionals, regardless of gender, capitalising on their talents and expertise, and facilitating value creation for the benefit of the individual, the economy and European society as a whole.

\section{Main desired facets:}

V1. Well founded reference model of the environment, specifying its: endogenous (structural, componential, functional, and behavioural) and exogenous (market, support, societal, constituency) elements, and their interlinks

V2. Well established technological infrastructure, support tools/services V3. Policies promoting changes in societal perceptions of age and support mechanisms to motivate and empower seniors, taking account of cultural differences, giving them the choice to continue their professional active life

V4. Established organizational infrastructures that support the interaction between senior professionals and other actors in the socio-economic system, facilitating value creation

V5. Established policies, legal frameworks and ethical principles regionally, nationally and across Europe - that motivate and support senior professionals and other socio-economic actors and regulate their interactions

In this research, to comprehensively cover the most important aspects related to a desired vision for ePAL, three main perspectives that are required to be addressed were identified. Namely, the vision of a desired future for active ageing shall cover its social perspective, its organizational perspective and its technological perspective. Tables 2, 3 and 4 show the instantiation of the ePAL vision according to these perspectives. 
TABLE 2. Vision - social perspective

In the coming decade, extending active professional life will be a high priority strategy across Europe. European societies will mature to accommodate demographic shift through supporting and empowering senior professionals to fulfil their potential as active participants in the economy. Attitudes amongst individuals and organisations will evolve to embrace senior professionals as a value-creating pool of talent, thereby supporting and promoting equal opportunities in active aging. Both senior and young professionals will derive greater benefit from the exchange of knowledge and experience. As the social environment evolves, new support mechanisms will arise to sustain an aging but more active and inclusive population.

\section{Main desired facets:}

VS1. New mechanisms to enhance positive understanding and perception in society regarding the value of the abilities, skills and experience of individual senior professionals in the economy, taking account of gender

VS2. Mechanisms to build awareness, and to motivate senior

professionals to join communities of active senior professionals

VS3. Mechanisms to support cross-cultural interactions among senior professionals as well as to the active labour force addressing barriers to communication

VS4. Mechanisms to support a balanced economic benefits sharing among the entire society including senior professionals

VS5. New mechanisms to help articulate the collective needs of seniors across national boundaries

VS6. Mechanisms to support cross generational interaction between seniors and younger citizens; fomenting inter-generational solidarity and understanding within the EU

VS7. Mechanisms to capitalize on the increased sense of trust and understanding which comes through leveraging seniors' social capital

TABLE 3. Vision - organizational perspective

In the coming decade, the primary organisational stakeholders governments, intermediaries, businesses and unions - will adopt positive, proactive and coordinated policies and approaches that enable seniors to choose to continue their professional active life. As a consequence, senior professionals will enjoy new opportunities and a new market space of senior skills will be created, benefiting businesses and strengthening the wider European economy.

\section{Main desired facets:}

VO1. Employment and retirement policies will change to provide greater flexibility for seniors to choose to continue as active economic participants

VO2. Regulations and policies will change to encourage businesses to collaborate with senior professionals, taking account of fair competition VO3. The knowledge and skills of seniors will be harnessed to generate value and stimulate innovation amongst European businesses

VO4. New forms of intermediate organizations will provide highly efficient brokerage that will create opportunities in line with market needs and that help seniors engage with businesses nationally and across Europe VO5. There will be sustainable funding models - from both public and private sectors - and the political drive to support new forms of senior associations and other intermediate brokers

VO6. All stakeholders will have access to the relevant training and other support services to facilitate the seniors' transition between working life and active retirement

VO7. New organizational cultures will positively embrace relationships between senior professionals and pre-retired (active) professionals
TABLE 4. Vision - technological perspective

In the coming decade, technology will facilitate and enable the continued active involvement of senior professionals in the socioeconomic system. Through engagement with end-users, novel ICT collaboration platforms and tools will be developed that catalyse the creation of new organisational forms that connect and empower all stakeholders and facilitate the interaction between them. This technology will be accessible to all, 'senior friendly' and will enable seniors to expand their capabilities, leave a legacy and create value.

\section{Main desired facets:}

VT1. Advanced collaboration support services, including (virtual) teams' formation and management

VT2. Development of collaboration ontology supporting variety of stakeholders

VT3. Support for user-generated knowledge assets

VT4. "Configure yourself "based philosophy infrastructure

VT5. Easily adaptable and customizable user interfaces

VT6. Affective computing and context aware enriched environments

VT7. Support for establishment of trust among stakeholders

VT8. Tools supporting the process of value creation

VT9. Novel contractual and cooperation agreements, including negotiation support

VT10. Advanced marketing and brokerage services

VT11. New networking models for elderly communities' involvement with the socio-economic system

VT12. Security and ethical / privacy support.

\section{Strategic ACtions}

The elaboration of a plan of strategic actions is a fundamental step in roadmapping. Such actions, when successfully implemented, shall take the society from the current situation, as reflected in the baseline, to a desirable future, as stated in the proposed vision. The process of formulating such actions starts with an intense brainstorming activity within a small group of experts.

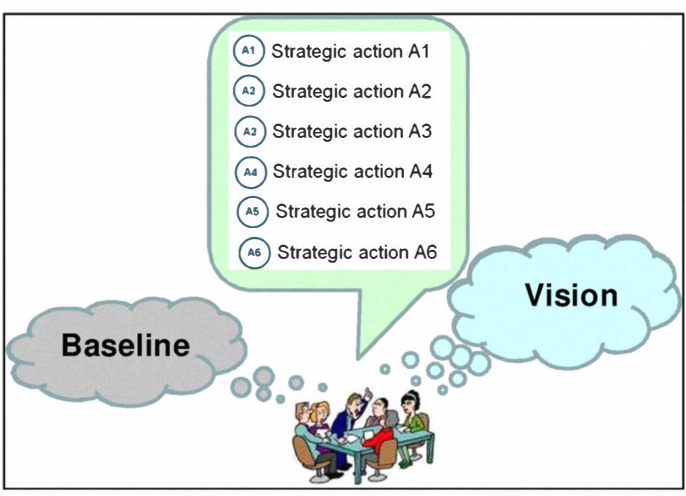

Figure 5. Brainstorming towards a plan of actions.

As implicit in Fig. 5, the gap analysis, i.e. the identification of the "distance" between the current situation and the desired future, is an important element in the process [10]. In this formulation some base principles were followed:

-Consider the needs according to the social, organizational, and technological perspectives of analysis and thus identify suitable actions for each of these areas.

- Keep the number of actions in each focus area relatively small (up to 6) in order to facilitate focused discussion. 
- Ensure that the proposed actions cover all stated facets of the vision.

- Propose actions that although ambitious, are feasible considering the current baseline and trends, and that take into account the results of the gap analysis.

The following tables introduce the proposed set of strategic R\&D actions that resulted from the roadmapping process conducted within the ePAL consortium and the extensive discussions held with stakeholders during the Consensus Building Events. The actions shown below reflect already the extensive feedback received in those events.

Considering the need to address technological developments within a socio-organizational context, the proposed actions are grouped into three major areas: social perspective actions, organizational perspective actions, and finally technological perspective actions.

TABLE 5. Proposed actions under the social perspective

\section{S1: Value identification and communication}

Promote socio-economic studies that identify the unique value senior workers bring to the workplace (experience, compensation flexibility, etc.) as well as their motivation and value systems, investigate new ways of senior workers interacting with the socio-economic system and communicate findings to seniors, employers, unions and to the society as a whole.

\section{S2: Leveraging skills and talents}

Design/develop mechanisms for skills/talent identification, categorization and improvement that assess acquired experience, provide career transition advice and support skills-enhancement to maximize the potential of seniors.

\section{S3: European Senior Space facilitation}

Promote dialogue and consensus around issues of technology, culture and socio-economic participation, creating links between existing and emerging senior associations and groups to develop a single, powerful voice for senior professionals across Europe.

\section{S4: Facilitating inter-generational interaction}

Investigate the barriers and potentials for cross generational interaction and collaboration between senior professionals and younger people, and fund/promote programmes and technology development that support and facilitate this interaction/collaboration.

\section{S5: Improving working practices}

Investigate new models of working practices and related reward and taxation models for senior professionals, taking account of issues of work-life balance, aging well and gender, and promote the findings in order to positively influence societal perception of older workers.

\section{S6: Developing training and awareness}

Design / develop ICT and collaboration training programs for seniors, and promote awareness and usage of collaboration technologies.
TABLE 6. Proposed actions under the organizational perspective

\section{O1: Enhancing policy and legislation}

Identify and assess current national and European policy, legislation and incentives relevant to active participation of seniors in the socio-economic system and recommend new approaches that lower barriers and promote and support active aging.

\section{O2: Keeping links}

Investigate new mechanisms that forge mutually beneficial relationships between seniors and their former employers

\section{O3: Creating organizational structures}

Investigate and promote new roles, governance rules and organizational forms for communities of active senior professionals to enhance inter- and intra-community collaboration and to create new opportunities for member engagement.

\section{O4: Improving mediation and brokerage}

Characterize and design new roles and modes of operation for intermediate organizations, both public and private, that provide brokerage and assistance to better facilitate integration and collaboration between senior professionals and the socioeconomic system.

\section{O5: Guiding career transition}

Define new programmes and realistic practices that prepare for and guide the successful transition of senior professionals from full employment to active retirement, taking account of issues of gender, profession and local context.

\section{O6: Meeting and creating market demand}

Explore the best fit between capabilities of senior professionals and market demand and identify new channels to harness these resources and potentials in order to generate value and stimulate innovation amongst European businesses, thus supporting the economy.

As previously mentioned, an important assumption in this roadmapping initiative is that the collaborative networks paradigm provides a useful context for more effective active ageing support. Therefore, the development of reference models, collaboration platforms, and collaboration support tools specifically oriented towards the facilitation of the continuation of the involvement of senior professionals in the socio-economic system is a major goal.

Certainly considerable progress has been made in recent years in the area of collaborative networks, accompanied by rapid developments in computer networks and web-based technologies. Thus the proposed actions for the technological perspective take account of these trends, and focus on the specificity of active ageing and particularly on support to the extension of active professional life.

As the main focus of ePAL is on a roadmap for ICT development, the actions under the technological perspective (Table 7) are more detailed than the actions under the other perspectives. 
TABLE 7. Proposed actions under the technological perspective

\section{T1: Developing conceptual models}

Establish formal conceptual models for people's professional life cycle and the support environment for active ageing.

T1.1 - Establish a reference model for extension of professional active life and active ageing.

T1.2 - Elaborate common ontologies for communities of senior professionals.

T1.3 - Develop contractual and business models for communities of senior professionals.

\section{T2: Generating adaptive solutions}

Develop and integrate self-adaptive and configurable technology solutions in ICT collaboration environments facilitating technology acceptance and enabling customization for/by seniors.

T2.1 - Develop self-adaptive interface systems.

T2.2 - Develop self-customizable collaboration environments empowering seniors to better use ICT.

T2.3 - Develop technology assistance wizards.

T2.4 - Increase involvement of seniors in the design of new technologies for seniors.

\section{T3: Building collaboration platforms}

Develop open ICT collaboration platforms for communities of senior professionals that promote human interaction and socialization and are enhanced by affective computing, context awareness, and trust establishment.

\section{T3.1 - Develop advanced functionalities and systems for management of communities of senior professionals.}

T3.2 - Develop affections / emotions management systems for communities of senior professionals.

T3.3 - Design and support governance systems for communities of senior professionals.

T3.4 - Develop trust building management systems for communities of senior professionals.

\section{T4: Building collaboration tools}

Design and develop collaboration support tools and systems to facilitate value creation, considering the specific needs of senior professionals.

T4.1 - Develop marketing and brokerage support tools for communities of senior professionals.

T4.2 - Develop tools for virtual team creation, negotiation and e-contracting.

T4.3 - Develop tools for virtual team management and collaborative problem solving support.

T4.4 - Develop models and tools for management of Intellectual Property and performance.

\section{T5: Leveraging legacy}

Develop environments that empower seniors to leave a legacy capitalizing on their valuable and transferable personal / professional experience.

T5.1 - Define conceptual models of talents and develop user-centred knowledge acquisition tools (e.g. Domain Specific Languages).

T5.2 - Create reward mechanisms (system of incentives) to attract user-generated knowledge.

T5.3 - Develop knowledge assets assessment and intellectual property models.

T5.4 - Mechanisms to promote inter-generational inheritance.

\section{T6: Elaborating behavioural models}

Develop approaches that discover patterns and model "the evolution of senior professionals' interests and their involvement in the socio-economic system" and "the behaviour and emotional health of senior professional networks".

T6.1 - Develop a conceptual base for behavioural modelling.

T6.2 - Develop data-mining / machine learning approaches for behavioural patterns discovery.

T6.3 - Develop forecasts and simulation methods and tools for behavioural analysis.

T6.4 - Develop models and tools for emotional health management.
The following diagrams show the proposed time sequence for the implementation of the actions.

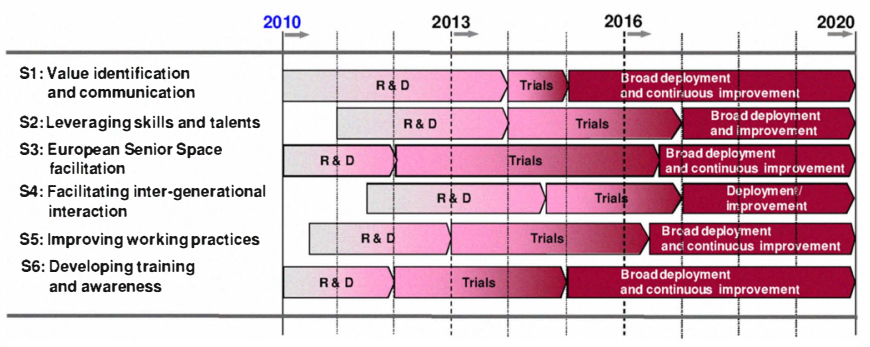

Figure 6. Time sequence for actions under the social perspective

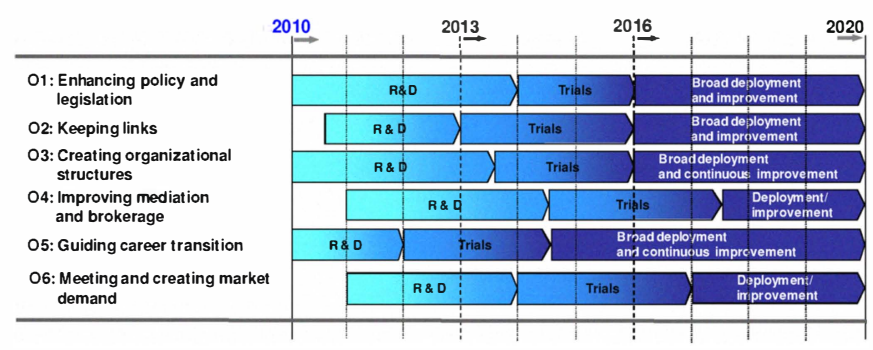

Figure 7. Time sequence for actions under the organizational perspective

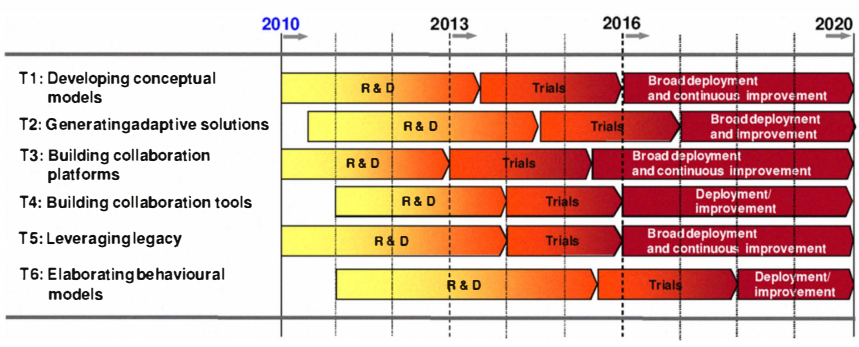

Figure 8. Time sequence for actions under the technological perspective

In the above diagrams three modalities of implementation are considered:

- $\underline{\mathrm{R} \& \mathrm{D}}$ - focusing on fundamental research and prototype development / proof of concept, aimed at addressing longer term challenges.

- Trials - oriented towards the development of pilots and validation scenarios that allow verification and refinement of the results of previous phase with the objective of facilitating the development of innovative products and services.

- Broad deployment and continuous improvement - aiming at large scale validation - large pilots - of new technologies and services, as a mechanism to facilitate their take-up by society.

\section{VALIDATION}

The proposed vision statements and strategic actions plan resulted from a multi-stage construction and validation process, as mentioned in Section II. An initial formulation was prepared by the ePAL consortium following a series of consultation workshops and brainstorming sessions. Once a set of strategic actions emerged as a result of the brainstorming exercise, it was then necessary to proceed with a verification of those actions. The adopted verification process, at this stage of the 
roadmapping process, comprised two main activities: (i) Verify that the set of proposed actions adequately cover all stated facets of the vision. (ii) Assess the feasibility of each action considering the results of the gap analysis. Figures 9 11illustrate the first step of validating the roadmap results.

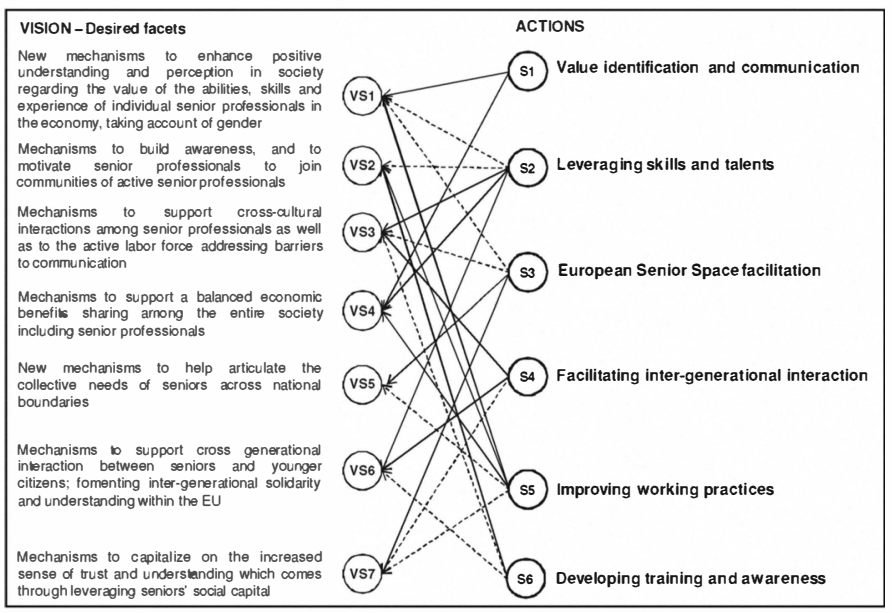

Figure 9. Covering the vision facets - social perspective

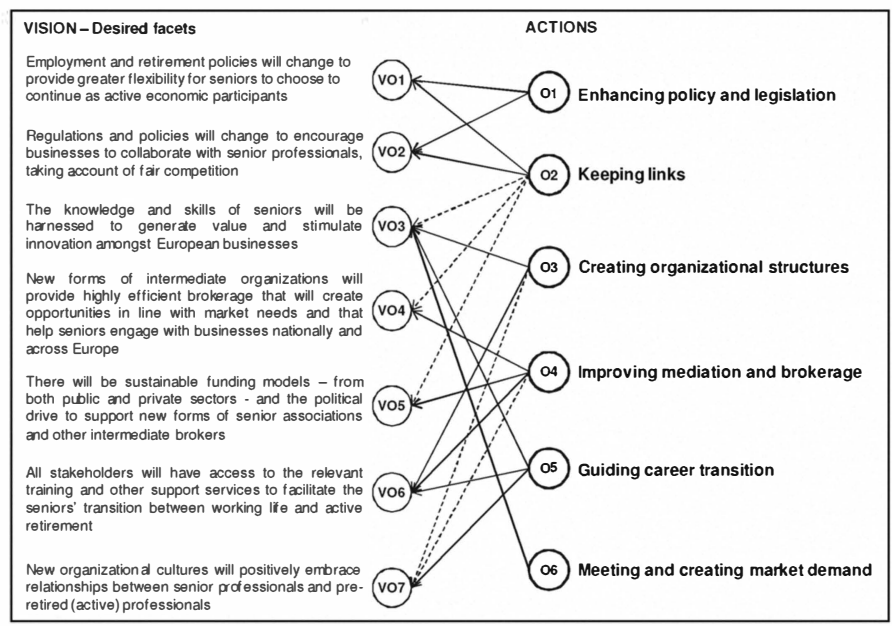

Figure 10. Covering the vision facets - organizational perspective

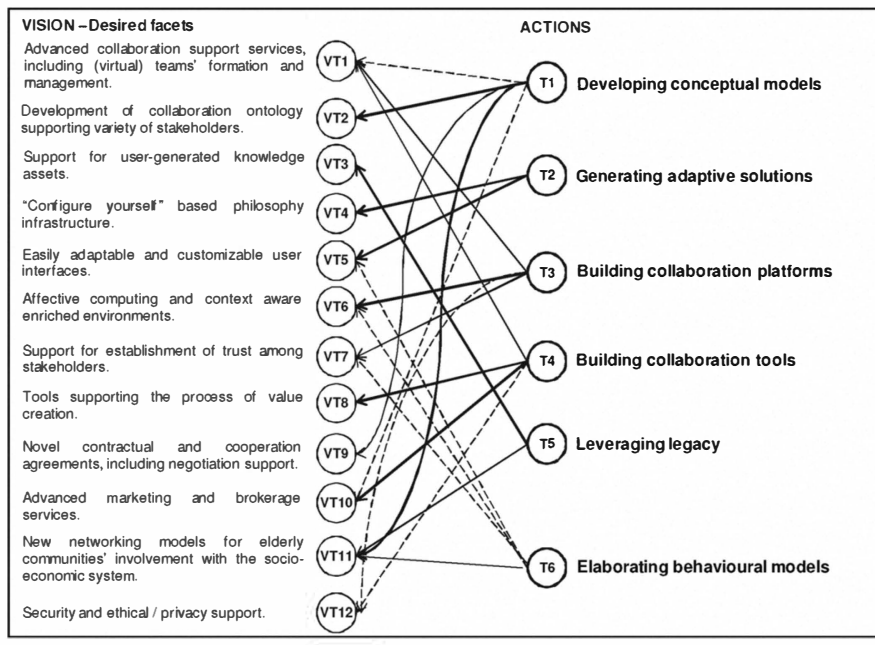

Figure 11. Covering the vision facets - technological perspective
Regarding the second step of validation, related to feasibility, the adopted approach was to consider how the strengths and limitations at European level identified in the gap analysis facilitate or make difficult the implementation of each action. Table 7 shows the result. This verification needed to be conducted by experts and depends on the perception of each individual according to his/her background knowledge. Therefore a qualitative scale (using terms such as Moderate, Hard, Very Hard) was adopted.

TABLE 7. Feasibility assessment

\begin{tabular}{clllll}
\hline $\begin{array}{c}\text { Social } \\
\text { perspective }\end{array}$ & \multicolumn{2}{c}{$\begin{array}{c}\text { Organisational } \\
\text { perspective }\end{array}$} & \multicolumn{2}{c}{$\begin{array}{c}\text { Technological } \\
\text { perspective }\end{array}$} \\
\hline S1 & Moderate & O1 & Hard & T1 & Very hard \\
S2 & Hard & O2 & Moderate & T2 & Very hard \\
S3 & Hard & O3 & Moderate & T3 & Moderate \\
S4 & Moderate & O4 & Very hard & T4 & Hard \\
S5 & Very hard & O5 & Hard & T5 & Very hard \\
S6 & Moderate & O6 & Very hard & T6 & Very hard \\
\hline
\end{tabular}

The last phase of the project was focused on the refinement and consensus-building among relevant stakeholders. For this purpose, a number of Consensus Building Events were organized in different regions of Europe, namely Porto, Seville, London, Madrid, Maastricht, Lisbon, and Thessaloniki, involving more than 150 experts from different fields.

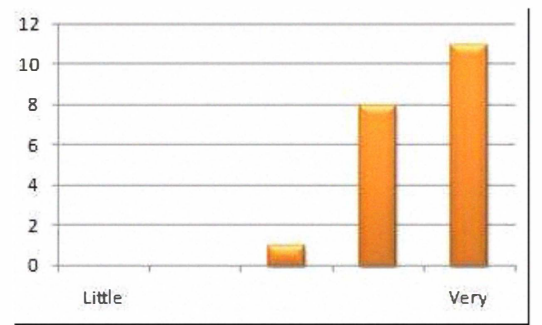

Figure 12. Example of agreement with ePAL vision

Fig. 12 illustrates the level of agreement with ePAL vision as voted by participants in one of these events. Fig.s 13-15 shows the level of prioritization of actions as a result of voting by the consulted stakeholders.

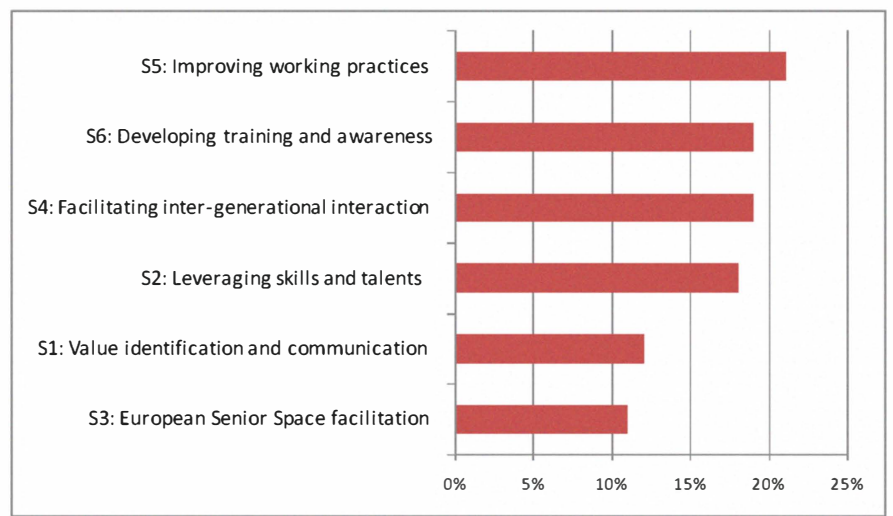

Figure 13. Prioritization of actions - social perspective 


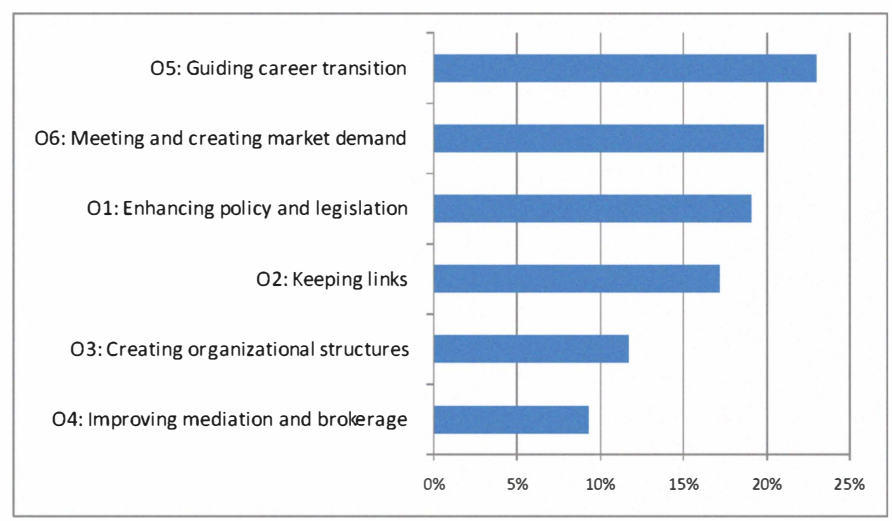

Figure 14. Prioritization of actions - organizational perspective

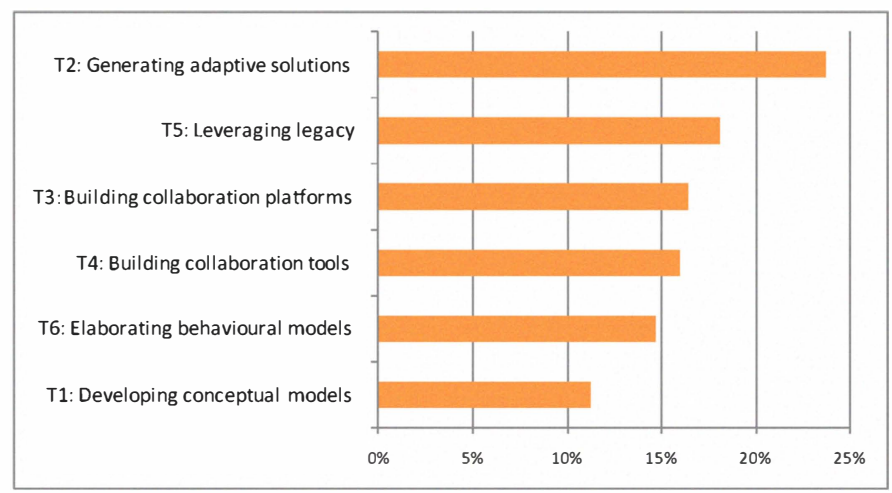

Figure 15. Prioritization of actions - technological perspective

This prioritization, combined with the expected difficulty identified in the feasibility assessment, can give decision makers important elements when deciding on research resources allocation.

\section{CONCLUSIONS}

As the expectancy of a longer, healthy life increases, the issue of extending the active professional life of senior people becomes an important topic. Such extension, if properly balanced with leisure and social activities, is likely to: (i) Facilitate active ageing, keeping seniors involved in, and contributing to, society; (ii) Generate additional income to help them maintain their standard of living and to support the wider economy.

Avoiding isolation and loneliness or even the creation of "elderly ghettos" is a major concern. ICT can be an important enabler in facilitating the creation of collaborative networks involving not only communities of seniors, but also potential recipients of their services and intermediary entities in a multilevel network. The collaborative networks paradigm supported by relevant technologies can also facilitate inter-generational interactions and thus contribute to the avoidance of ghettos.
Given the lessons from early experiences of technological developments focused on older people and the sensitivity of the area, future RTD needs to be supported by carefully designed roadmaps. In this direction, results from ePAL offer a strategic RTD roadmap that considers not only advanced technological developments but also the needed social and -organizational transformations.

The systematic roadmapping process behind the proposed research agenda, as well as the extensive validation process involving a large community of stakeholders, are important factors for providing confidence in the adequacy of the proposed roadmap. Nevertheless, as normal in any "futures planning" initiative, a roadmap is a dynamic construct that needs to be periodically revised alongside its implementation, taking into account new trends as they inevitably emerge.

\section{ACKNOWLEDGMENT}

This work was funded in part be the European Commission through the ePAL project. The authors also thank the contribution of their partners in the ePAL project as well as the multiple stakeholders involved in the consensus building workshops for their contribution to the roadmap.

\section{REFERENCES}

[1] HSBC Insurance, "The future of retirement - The new old age". May 2007.

www.hsbc.com/1/PA_1 1 _ S S5/content/assets/retirement/gender_perspecti ve eurasia_africa_1.pdf

[2] WHO, "Active Aging: A Policy Framework" WHO/NMH/NPH/02.8, World Health Organisation report 2002.

[3] P. Wilson, K. Johnson, and W. Buller, "Ageing well in a connected world: Smarter care, smarter participation". CISCO Internet Business Solutions Group, Dec 2008.

[4] L. M. Camarinha-Matos, H. Afsarmanesh, "Collaborative mechanisms for a new perspective on active ageing", in Proceedings of DEST 2009 - 3rd IEEE Int. Conference on Digital Ecosystems and Technologies, 1-3 Jun 2009, Istanbul, Turkey.

[5] L. M. Camarinha-Matos, and H. Afsarmanesh, "The Need for a Strategic R\&D Roadmap for Active Ageing", in Leveraging knowledge for innovation in Collaborative Networks (L. M. Camarinha-Matos, I. Paraskakis, H. Afsarmanesh, Eds.), Springer, pp. 669-680, 2009.

[6] J. C. Collins, and J. I. Porras, "Organizational vision and visionary organizations". In Leading organizations - Perspectives for a new era, $\mathrm{pp}$ 234-249, SAGE, 1998.

[7] L. M. Camarinha-Matos, H. Afsarmanesh, "A roadmapping methodology for strategic research on VO", in Collaborative Networked Organizations - A research agenda for emerging business models, cap. 7.1, Springer, 2004.

[8] H. Afsarmanesh, L. M. Camarinha-Matos, and S. Msanjila, "A Wellconceived Vision for Extending Professional Life of Seniors", in Leveraging knowledge for innovation in Collaborative Networks (L. M. Camarinha-Matos, I. Paraskakis, H. Afsarmanesh, Eds.), Springer, pp. 681-692, 2009.

[9] T.G. Cummings, Organization Development and Change. Thomson SouthWestern, 2005.

[10] W. Leonard, H. Afsarmanesh, S. Msanjila, and J. Playfoot, "Exploring the Gap for Effective Extension of Professional Active Life in Europe", in Leveraging knowledge for innovation in Collaborative Networks (L. M. Camarinha-Matos, I. Paraskakis, H. Afsarmanesh, Eds.), Springer, 2009. 